Supplement of Clim. Past, 13, 1007-1022, 2017

https://doi.org/10.5194/cp-13-1007-2017-supplement

(C) Author(s) 2017. This work is distributed under

the Creative Commons Attribution 3.0 License.

(c) (i)

Supplement of

\title{
Experiments based on blue intensity for reconstructing North Pacific temperatures along the Gulf of Alaska
}

\section{Rob Wilson et al.}

Correspondence to: Rob Wilson (rjsw@st-andrews.ac.uk)

The copyright of individual parts of the supplement might differ from the CC BY 3.0 License. 


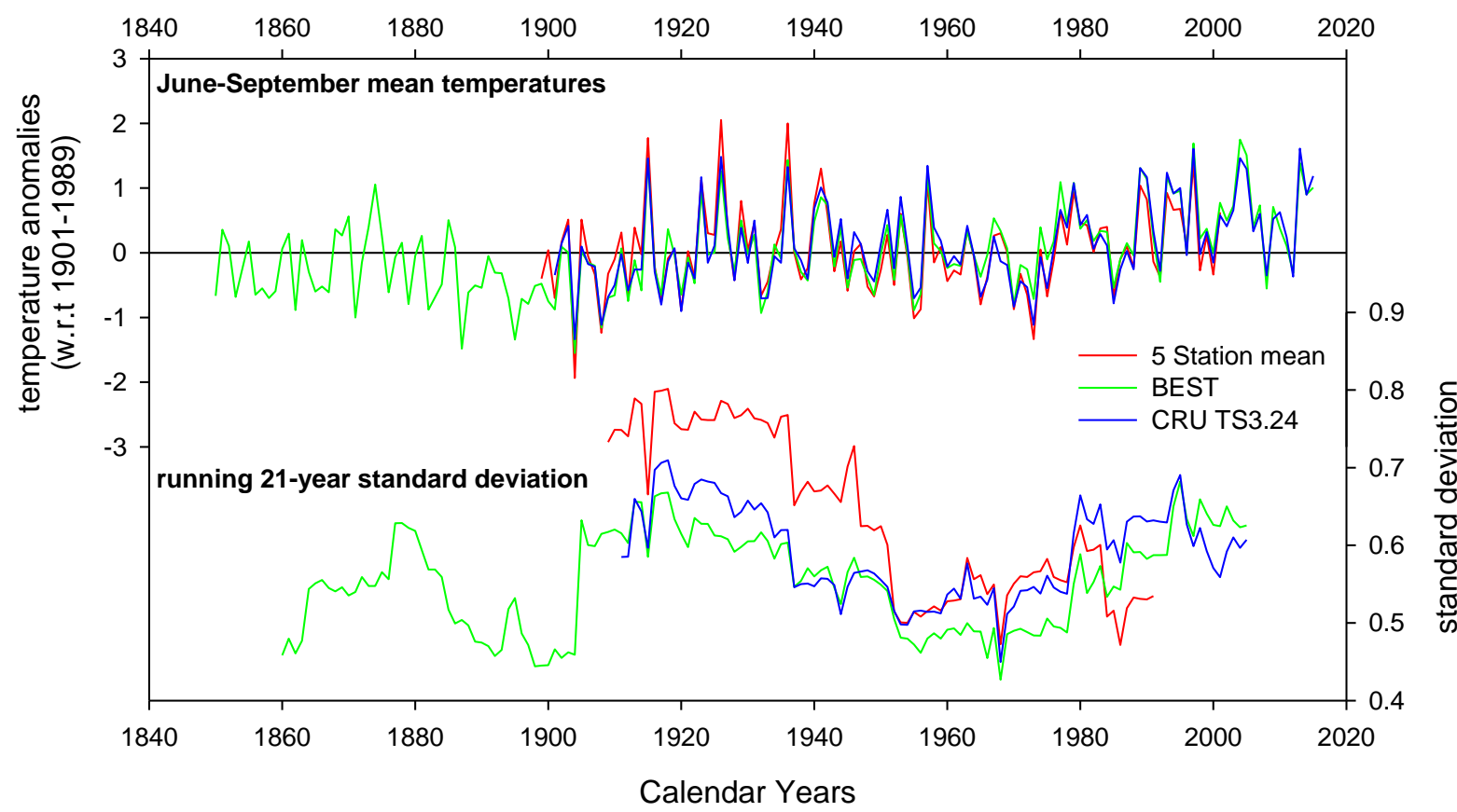

Figure S1: Comparison between the GOA 5 station mean instrumental record (Wilson et al. 2007, Wiles et al. 2014) and gridded (57-61N / 154-134W) JJAS temperatures using CRU TS3.24 and BEST. The upper plots present anomalies with respect to 1901-1989, while the low panel presents running 21-year plots of standard deviation. 

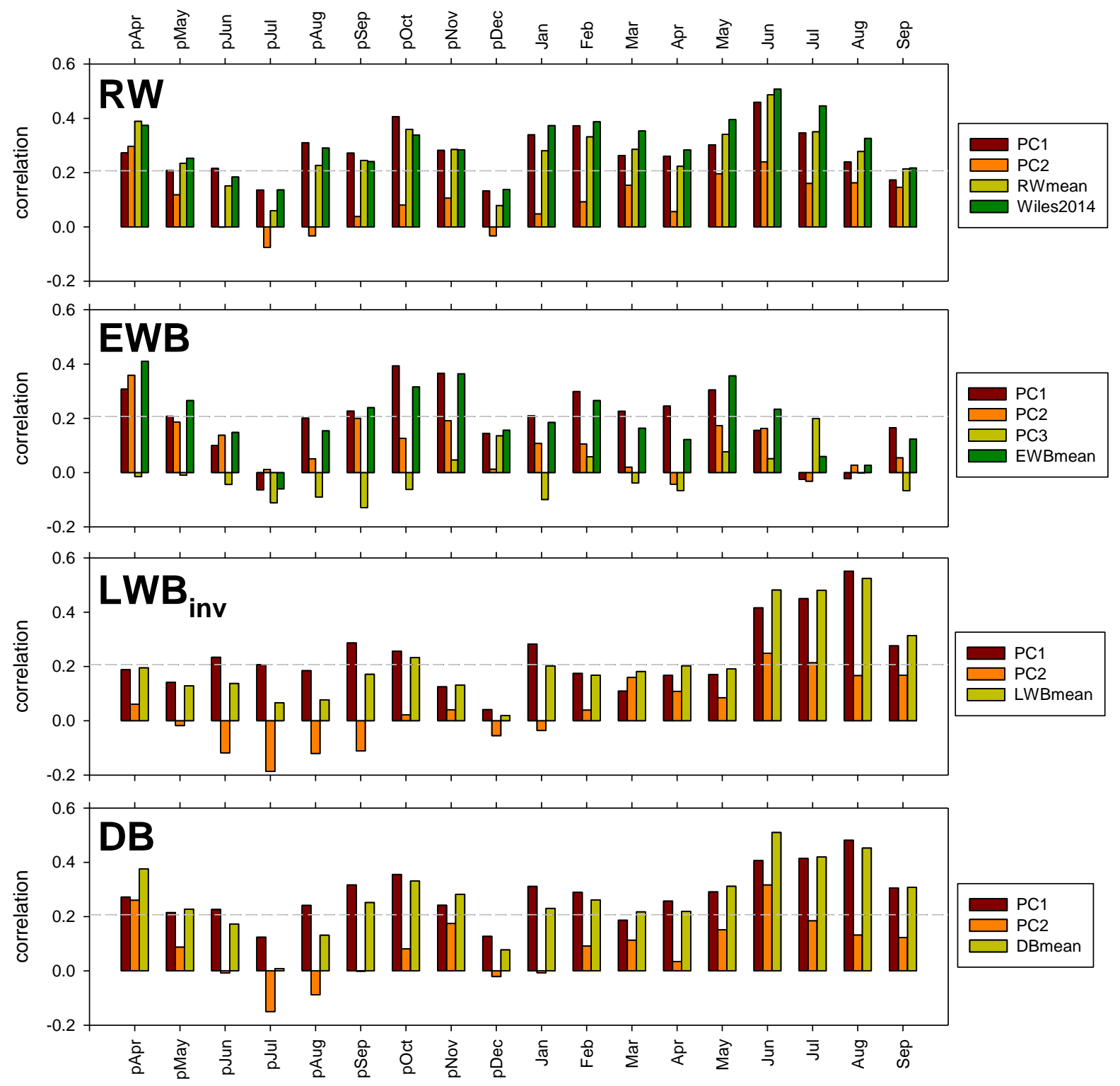

Figure S2: Correlation response function analysis (1901-1989 using CRU TS3.24 mean temperatures for region 57-61N / 154-134W) for each tree-ring variable. The bars represent correlations with monthly series of temperature for each PC and the simple GOA mean composite for each variable. Also for RW, correlations are shown for the Wiles et al. (2014) RW based reconstruction. Horizontal dashed line denotes the $95 \%$ confidence limit. Correlations against the seasons are presented in Figure 2 of the main paper. 

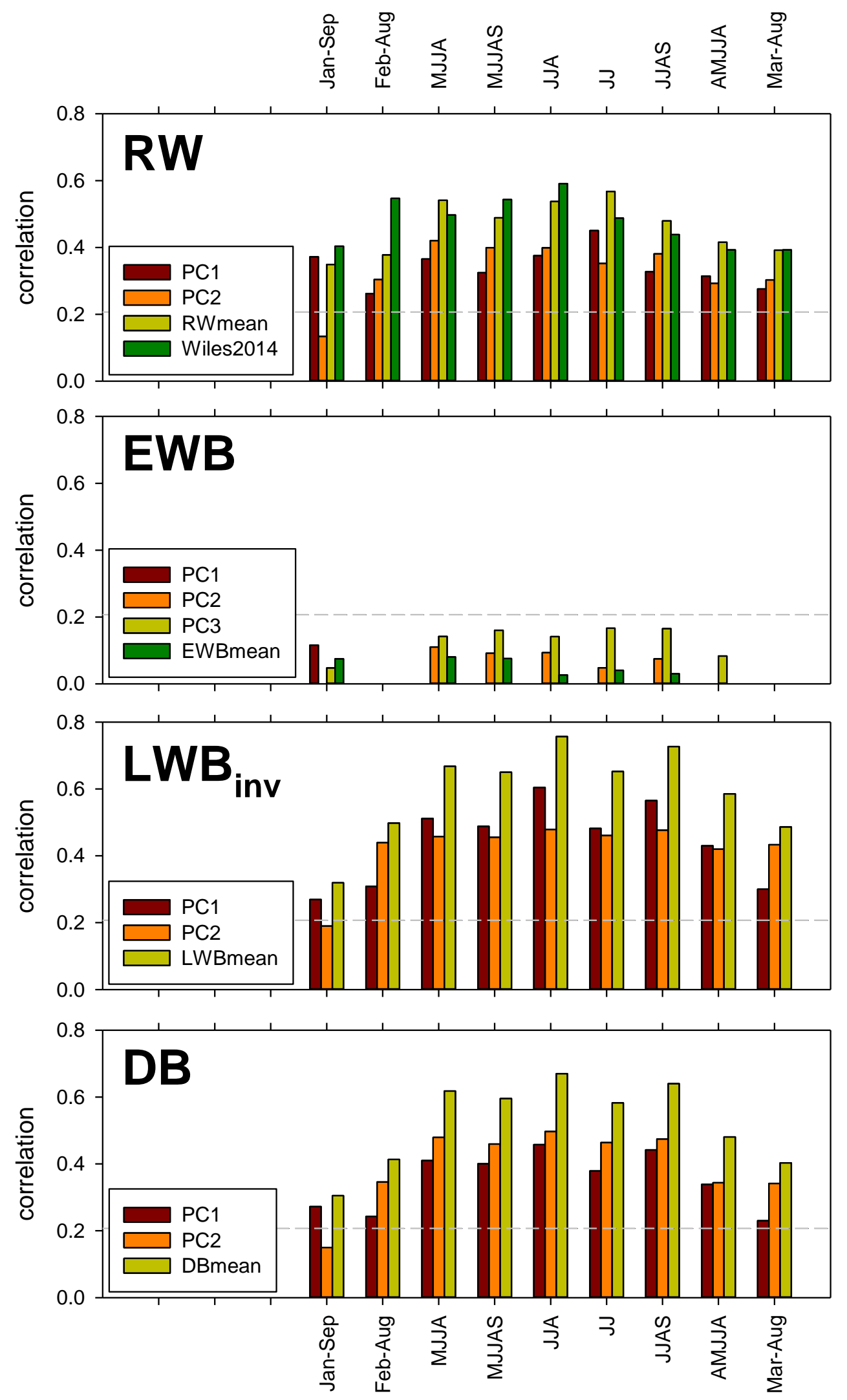

Figure S3: As with Figure 2, Correlation response function analysis (1901-1989) using CRU TS3.24 mean temperatures but the data have been transformed to $1^{\text {st }}$ differences prior to analysis. 

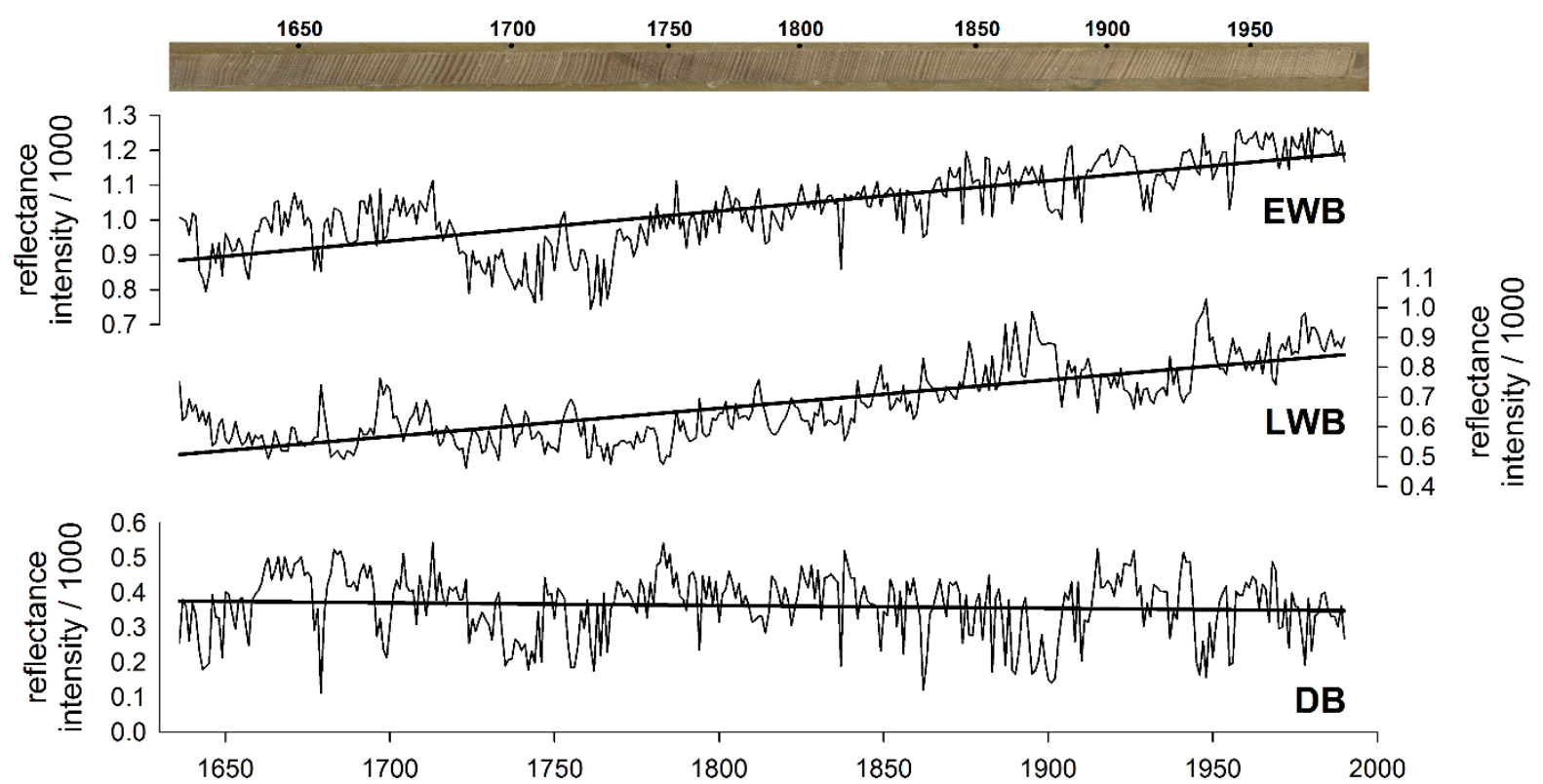

Figure S4: Example raw EWB, LWB and DB values for a single sample (01NE) from the Ellsworth site. Linear trends of the time-series are shown. 


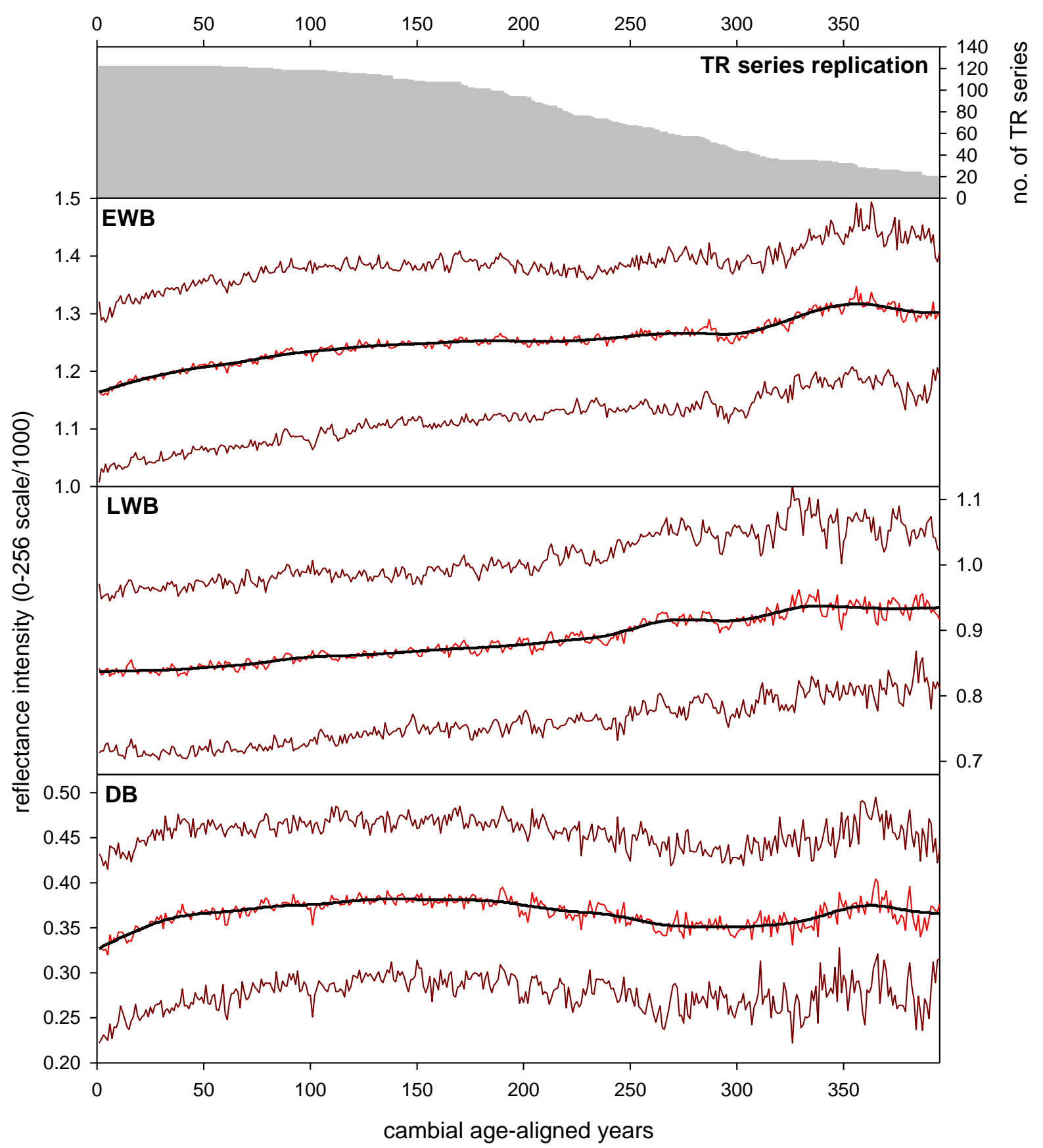

Figure S5: Cambial age-aligned mean curves of the full 8 site combined GOA data-set. Pith-offset values were not utilised. The LWB data have not been inverted for this figure. 